\title{
Resultados Empíricos do Mapeamento do Fluxo de Valor em Uma Empresa Automotiva
}

Oydil Cesar de Figueiredo oydil@hotmail.com

Universidade Federal fluminense (UFF), Niterói, Rio de Janeiro, Brasil

Ualison Rébula de Oliveira ualison.oliveira@gmail.com

Universidade Federal fluminense (UFF), Niterói, Rio de Janeiro, Brasil

\author{
RESUMO
}

A necessidade de reduzir os desperdícios que consomem recursos e não agregam valor leva as empresas a aplicar os conceitos de Manufatura Enxuta resultando em ganhos significativos para a companhia. Entendendo esse problema, o estudo utiliza a ferramenta de Mapeamento do Fluxo de Valor (VSM) por meio de uma pesquisa-ação aplicada em uma empresa de autopeças da região Sul Fluminense, objetivando-se aplicar as técnicas Lean Manufacturing e medir os resultados. Nessa análise empírica o VSM identificou desperdícios no processo estudado, motivando a aplicação das ferramentas da qualidade, manutenção produtiva total, fluxo contínuo, sistema puxado e trabalho padronizado, resultando em um aumento da produtividade em $91,66 \%$, elevação do OEE em $18 \%$, redução da movimentação de 72 para 6 metros, além de simplificar o processo produtivo eliminando 3 etapas.
\end{abstract}

PALAVRAS-CHAVE: Produção Enxuta. Mapeamento de Fluxo de Valor. Desperdício 


\section{INTRODUÇÃO}

Observa-se na atualidade que a competitividade global obriga as empresas a se adequarem aos custos produtivos praticados pelo mercado mundial, buscando, para isso, filosofias de gestão eficiente de operações. Esse desafio motiva as empresas a repensarem suas estratégias de gestão e seus processos produtivos, pois descobriu-se com o passar dos anos, que ser apenas produtivo não bastava; tornou-se necessário adequar a quantidade produzida à demanda do cliente e reduzir os custos de operação para ser competitivo frente à concorrência. A competição global, o ambiente de demanda incerta e elevação das expectativas dos consumidores estão entre muitos motivos para que as empresas adotem os princípios e ferramentas de Manufatura Enxuta (DEIFA e ELMARAGHY, 2014).

Com o aumento da competitividade as organizações têm procurado eliminar o valor não-agregado, elevando a eficiência e a qualidade nas suas operações. A mentalidade enxuta ganhou força, pois sua essência é a busca pela melhoria da performance através da redução dos desperdícios, que segundo Prates e Bandeira (2011), são atividades que demandam recursos, mas não agregam valor. A Manufatura Enxuta é o caminho para se obter vantagem competitiva pois a redução dos desperdícios está fortemente ligada à melhoria da competitividade (SAURIN et al, 2010).

As empresas de autopeças aplicam amplamente essas técnicas, alavancando a melhoria de seus processos. Entre outros, temos: Uhrin, Cámara, e Fuentes (2017) que apresentam a relação entre a performance operacional e o Lean em fornecedores da indústria automotiva; Marodin et al (2016) em um assessment no supply chain das industrias automotivas identificou que as empresas que aplicam a Manufatura Enxuta tem melhor performance; Peinado e Graeml (2014) em uma pesquisa com as montadoras identificaram a Manufatura Enxuta como uma prática altamente valorizada; Gobbo et al (2010), afirmam que a indústria automobilística mundial adota a Manufatura Enxuta como estratégia de produção; Marodin, Eckert e Saurin (2012) adotam o sistema de logística enxuta influenciando positivamente nos indicadores de desempenho do sistema produtivo de uma montadora de veículos; Losonci, Demeter e Jenei (2011) examinam a percepção dos colaboradores durante a implementação da filosofia em uma indústria automotiva; Duarte e Cruz (2017) analisam o nível de implementação Lean em diferentes indústrias do setor; Saurin, Ribeiro e Marodin (2010) em seu levantamento da implantação enxuta no Brasil e exterior evidenciam que o setor mais representativo é o automotivo; Jabbour et al (2013) analisaram a relação entre Manufatura Enxuta e desempenho operacional de empresas do setor automotivo no Brasil; O Lean é aplicado prioritariamente nas áreas automotiva e aeroespacial (BHAMU, SANGWAN, 2014; JASTI, KODALI, 2014); Freitas et al (2014) analisaram 75 empresas do ramo automotivo relacionando gestão de recursos humanos e a Manufatura Enxuta; Mesquita, Mesquita e Souza (2014) aplicam as técnicas em uma montadora de veículos, denominada empresa Beta; Moura e Botter (2002) abordam o gerenciamento de materiais JIT utilizados pelas indústrias automobilísticas nacionais.

Diversos autores aplicaram o Mapeamento do Fluxo de Valor objetivando identificar os desperdícios e atacá-los. Cita-se como exemplos: Royer, Ferreira e Savedra (2018); Pinto et al (2017); Rodríguez (2017); Filho e Pires (2017); 
Barbalho, Nitzsche e Dantas (2017); Bueno e Veiga (2016); Jeong e Yoon (2016); Lima et al (2016); Calsavara (2016); Das, Venkatadri e Pande (2014); Mesquita, Mesquita e Souza (2014); Rajenthirakumar e Sridhar (2014); Votto e Fernandes (2014); Milnitz e Tubino (2013); Bartz et al (2013); Dal et al (2013); Vinodh et al, (2013); Teichgräber e Bucourt (2012); Rajenthirakumar e Shankar (2011); Ramesh, e Kodali (2011); Prates e Bandeira (2011); Salgado et al (2009); Roldan e Miyake (2004); Lima e Zawislak (2003); nesse sentido propõe-se como objetivo principal desse trabalho investigar as oportunidades de melhoria em um processo produtivo de uma empresa de autopeças, utilizando o Mapeamento de Fluxo de Valor, também conhecido como Value Stream Mapping para coleta e análise de dados, aplicando as técnicas Lean Manufacturing e posteriormente medindo os seus resultados. Esse método é sistematicamente suportado por uma pesquisaação dividida em três etapas: (1) Selecionar uma família de produtos; (2) Desenhar o estado atual e o futuro e; (3) Preparar um plano de implementação.

Quanto à estrutura desse trabalho, na seção 2 é apresentada a revisão da literatura, seguido do método de pesquisa na seção 3; na seção 4 expõem-se os resultados obtidos com a aplicação da pesquisa-ação; na seção 5 analisam-se os resultados; e finalizando o artigo encontram-se as conclusões, seguido das referências bibliográficas.

\section{REVISÃO BIBLIOGRAFICA}

Esta seção apresenta uma breve revisão da bibliografia, segmentada nos seguintes temas: a) Manufatura Enxuta; b) Mapeamento do Fluxo de Valor; c) Ferramentas da qualidade e Manutenção produtiva total; d) Indicador de desempenho OEE; e) Fluxo contínuo e Sistema puxado; f) Trabalho padronizado conforme segue.

\section{MANUFATURA ENXUTA}

A Manufatura Enxuta ou Lean Manufacturing nasceu das técnicas aplicadas pela Toyota no Japão, decorrente de sua busca contínua pela redução de desperdícios tornando-se modelo de referência seguido por indústrias do mundo inteiro. Essa filosofia busca adequar sua produção em conformidade com a demanda do cliente, ou seja, produzir conforme o Takt time, que é o tempo teórico para produzir uma peça solicitada pelo cliente (Gautam et al 2012), ou seja, o tempo disponível para a produção, dividido pela demanda do cliente.

Marchwinski e Shook (2007) relatam também que a vantagem estratégica originada pela mentalidade enxuta é alcançada pela eliminação dos sete principais desperdícios normalmente encontrados na produção em massa. Segundo Silva et al (2011) deve-se eliminar os desperdícios promovendo a identificação do que agrega valor na perspectiva do cliente. O pensamento enxuto é uma forma de fazer cada vez mais com cada vez menos. Menos esforço humano, menos equipamento e menos espaço, fornecendo aos clientes o que eles efetivamente desejam, através de eliminação de sete desperdícios clássicos: (1) Produção em excesso; (2) Espera; (3) Transporte; (4) Processamento; (5) Estoque; (6) Movimentação; (7) Correção. (RAVE et al 2011). No quadro abaixo citam-se exemplos para os sete desperdícios 
Quadro 1 - Exemplos para os sete desperdícios

\begin{tabular}{|l|l|}
\hline \multicolumn{1}{|c|}{ Desperdícios } & \multicolumn{1}{c|}{ Exemplos } \\
\hline Produção em excesso: & $\begin{array}{l}\text { Produzir além da necessidade do próximo processo ou } \\
\text { cliente. Produzir sob demanda especulativa. É a pior } \\
\text { forma de desperdício, pois contribui para a ocorrência } \\
\text { dos outros seis. }\end{array}$ \\
\hline Espera: & $\begin{array}{l}\text { Operadores esperando enquanto máquinas operam; } \\
\text { Esperando por manutenção enquanto os equipamentos } \\
\text { estão em falha; Esperando pelo abastecimento logístico } \\
\text { de peças necessárias que não são entregues a tempo. }\end{array}$ \\
\hline Transporte: & $\begin{array}{l}\text { Movimentação desnecessária de produtos ou peças, } \\
\text { como de uma etapa de processamento a um } \\
\text { almoxarifado e dali a uma etapa do processo, quando a } \\
\text { segunda etapa poderia estar localizada ao lado da } \\
\text { primeira. }\end{array}$ \\
\hline Processamento: & $\begin{array}{l}\text { Realizar etapas desnecessárias ou incorretas, geralmente } \\
\text { devido a equipamento ou projeto ruim. }\end{array}$ \\
\hline Estoque: & $\begin{array}{l}\text { Possuir estoques maiores que o mínimo necessário para } \\
\text { um sistema puxado e controlado. }\end{array}$ \\
\hline Movimentação: & $\begin{array}{l}\text { Operadores realizando movimentações desnecessárias } \\
\text { tais como procurar ferramentas, peças ou documentos, } \\
\text { etc }\end{array}$ \\
\hline Correção: & \begin{tabular}{l} 
Inspeção, retrabalho e refugo. \\
\hline
\end{tabular}
\end{tabular}

Fonte: Adaptado de Marchwinski e Shook (2007)

Bartz et al (2013) recomenda o uso do mapeamento do fluxo de valor como ferramenta indispensável na identificação de desperdícios existentes na organização, pois eleva o nível de qualidade através da melhoria contínua direcionando a empresa aos princípios Lean, proporcionando maior integração entre todas as etapas da produção.

\section{MAPEAMENTO DO FLUXO DE VALOR}

O Value Stream Mapping é uma ferramenta que identifica os desperdícios e suporta a implantação das melhorias (JEONG e YOON, 2016). Segundo Rajenthirakumar e Shankar (2011) o mapeamento do fluxo de valor é uma ferramenta que visualiza as atividades que agregam ou não agregam valor e que são realizadas por uma empresa para projetar, produzir e entregar seus produtos (bens ou serviços) aos clientes. O mapeamento de fluxo de valor é uma ferramenta para investigação do processo que possibilita a visualização de toda a cadeia de valor visando eliminação progressiva dos desperdícios (Teichgräber e Bucourt, 2012; Ar e Al-ashraf, 2012). O mapa do fluxo de valor identifica os desperdícios nas atividades e realiza melhorias de forma estruturada e objetiva (Milnitz e Tubino, 2013).

Para Jones e Womack (2004) a vantagem do mapeamento do fluxo de valor é desagregar problemas no nível dos produtos específicos, melhorando o processo de solução de problemas pelos gerentes. Para fazer isso, é preciso começar do ponto mais distante fluxo abaixo (no sentido do cliente).

Dal et al (2013) evidenciaram ganhos com: (1) a redução de estoques; (2) redução no tempo de entrega; (3) qualidade; e (4) produtividade da linha através 
do mapeamento de fluxo de valor aplicado em uma indústria. Ganhos também apresentados por Vinodh et al (2013), ao explorarem o processo de fabricação do produto "espaçador", por meio do método de estudo de caso, trazendo como resultados uma indicação positiva de que, caso implantado, as ações trariam benefícios e direcionariam a empresa rumo à filosofia enxuta, aumentando sua competitividade no mercado global.

Jones e Womack (2004) fazem referência ao mapeamento de fluxo de valor como uma ferramenta gráfica representando todo o fluxo de informações e processos de uma cadeia de valor, buscando pontos de melhoria e eliminação dos desperdícios, por meio do simples processo de observação dos fluxos de informação e de materiais conforme eles ocorrem, resumindo-os visualmente e vislumbrando um estado futuro com melhor desempenho.

\section{FERRAMENTAS DA QUALIDADE E MANUTENÇÃO PRODUTIVA TOTAL}

A qualidade e a produtividade estão entre os diversos fatores críticos de sucesso que as empresas devem considerar (SILVA et al, 2011). Redução dos custos e aperfeiçoar a qualidade são consequências da operação produtiva em um sistema de gestão baseado no Lean Manufacturing (PRATES e BANDEIRA, 2011; PEINADO e GRAEML, 2014).

Para Raposo (2011) a implantação da TPM proporciona a realização de melhorias significativas para a empresa. Deifa e Elmaraghy (2014); Mendes e Ribeiro (2014) descrevem que a manutenção é fundamental para que se possa alcançar a estabilidade do processo, aumentando a disponibilidade da linha. 0 TPM garante que os equipamentos trabalhem sem avarias ou falhas, eliminando as perdas e melhorando a confiabilidade dos equipamentos (CELIS e GARCÍA, 2012). O aumento da disponibilidade reduz o custo de manutenção e o tempo de reparo, aumentando o tempo entre falhas (BIEHL e SELLITTO, 2015).

\section{OEE - OVERALL EQUIPMENT EFFECTIVENESS}

O OEE (Overall Equipment Effectiveness) é uma medida de desempenho composta por três parâmetros: (1) performance; (2) qualidade; e (3) disponibilidade em cada etapa da produção (DOMINGO e AGUADO, 2015). OEE (Overall Equipment Effectiveness) ou Eficiência Global do Equipamento (ou de uma célula) é um indicador que mede simultaneamente a disponibilidade, o desempenho e a qualidade (SILVA et al, 2011). O OEE tem sido empregado para medir o desempenho individual de um equipamento (SILVA et al, 2016), com o objetivo de melhorar a confiabilidade e a capacidade das máquinas por meio de manutenções periódicas (FREITAS et al, 2014). Este indicador resulta do seguinte produto: $\mathrm{OEE}=$ Disponibilidade $\times$ Desempenho $\times$ Qualidade .

- Performance: é a capacidade que o operador tem de respeitar o tempo estipulado para a operação;

- Qualidade: é a capacidade que o processo tem de produzir peças boas, excluindo os refugos, retrabalho (peças que retornam da inspeção final), downtimes causados por problemas de qualidade; 
- Disponibilidade: é a porcentagem do tempo que a linha fica disponível para produção retirando os tempos de quebras do equipamento, setup, limpeza, falta de material, reuniões, etc.

\section{FLUXO CONTÍNUO E SISTEMA PUXADO}

As atividades logísticas por meio da implementação e controle do fluxo dos materiais elevam o nível de competitividade de uma empresa (JÚNIOR, SILUK e NARA, 2015). O fluxo contínuo se caracteriza pelo fluxo unitário de peças, produzindo e movimentando um item por vez, ao longo de uma série de etapas (VOTTO e FERNANDES, 2014; BARTZ, WEISE e RUPPENTHAL, 2013). Nesse fluxo as etapas são interligadas e os produtos fluem sem interrupções e sem estoque (MACEDO et al, 2014), gerando um mecanismo indutor de melhoria de todo o sistema de produção (BULHÕES e PICCHI, 2011). Barbosa, Carvalho e Filho (2014) citam alguns benefícios do fluxo contínuo, tais como: (1) processo sem refluxo; (2) melhor aproveitamento do layout; (3) redução de tempo de setup; (4) flexibilização do processo para atender às oscilações da demanda; e (5) melhoria da segurança e ergonomia, além da liberação de área para o processo produtivo (MARODIN e SAURIN, 2013)

O sistema puxado trabalha a partir da autorização de produção pelo processo cliente (RIEZEBOS, 2013). Para Rebelato, Madaleno e Rodrigues (2012), o sistema puxado determina que o material somente seja processado no momento necessário e nas quantidades que serão indispensáveis para o seu uso imediato. Produz-se em todas as etapas apenas os itens necessários em quantidades necessárias e no tempo requerido (MELLO e FASSINI, 2017), trazendo como benefício à redução dos estoques (CELIS e GARCÍA, 2012).

\section{TRABALHO PADRONIZADO}

Para se conseguir desempenho consistente é necessário o estabelecimento de processos e procedimentos padronizados (BERKENBROCK et al, 2009). Para Marodin e Saurin (2013) o trabalho padronizado está diretamente ligado distribuição das atividades entre operadores da melhor forma possível, buscando a redução dos desperdícios de tempo de movimentação de operadores entre operações. Para Rajenthirakumar e Sridhar (2014) o balanceamento é como os operadores desempenham suas atividades e como elas podem ser otimizadas. Segundo Zattar, Silva e Boschetto (2017) o trabalho padronizado é o estabelecimento de procedimentos precisos para o trabalho de cada um dos operadores em um processo de produção.

Os operadores que atuam com o trabalho padronizado tem maior flexibilidade exigindo grande conhecimento e habilidade (AZZAM; ARIAS e ZHOU, 2011), trazendo ganhos significativos na produtividade (GAUTAM; KUMAR e SINGH, 2012).

\section{METODOLOGIA}

Para a consecução dos objetivos da presente pesquisa, esse trabalho contou com uma pesquisa bibliográfica e uma pesquisa empírica. Para desenvolvimento 
do referencial teórico, efetuou-se uma pesquisa bibliográfica em periódicos nacionais e internacionais, em títulos relacionados ao tema Lean Manufacturing.

No que tange a pesquisa empírica, utilizou-se de uma pesquisa-ação, escolhida por ser o método que melhor descreve o envolvimento do pesquisador no processo de pesquisa. Para a composição da pesquisa-ação, aplicou-se o Mapeamento de Fluxo de Valor por meio de uma sequência de atividades adaptadas de Rother e Shook (2012), posteriormente validadas por Royer, Ferreira e Savedra (2018), conforme Quadro 2.

Quadro 2 - Informações metodológicas da pesquisa

\begin{tabular}{|l|l|}
\hline \multicolumn{1}{|c|}{ Etapas } & \multicolumn{1}{c|}{ Atividades } \\
\hline $\begin{array}{l}\text { Primeira etapa: } \\
\text { Selecionar uma família } \\
\text { de produtos. }\end{array}$ & Analisar as linhas existentes e definir as famílias de produtos. \\
\hline $\begin{array}{l}\text { Segunda etapa: } \\
\text { Desenhar o estado } \\
\text { atual e o futuro. }\end{array}$ & $\begin{array}{l}\text { Ao mapear o estado atual, escolhe-se um componente } \\
\text { principal a ser seguido. A partir de seu fornecedor é } \\
\text { desenhado seu caminho, passando pela empresa e chegando } \\
\text { até o cliente. Descrevendo sua frequência de entrega, } \\
\text { quantidades de estoque entre os processos, tempo de } \\
\text { agregação de valor, tempo ciclo das operações, tempo de } \\
\text { setup, quantidade de turnos e demais informações que se } \\
\text { achar relevante para identificar a situação atual. }\end{array}$ \\
\hline $\begin{array}{l}\text { Terceira etapa: } \\
\text { Preparar um plano de } \\
\text { implementação. }\end{array}$ & $\begin{array}{l}\text { Criar um plano de ações que descreva essa transição do } \\
\text { estado atual para o estado futuro; e tão breve possível, } \\
\text { colocá-lo em prática. }\end{array}$ \\
\hline
\end{tabular}

Fonte: adaptado de Royer, Ferreira e Savedra (2018)

Etapa 1: definição da família de produtos: a escolha da família de produtos baseou-se na similaridade de processos que compartilham a mesma linha de produção. Para definição da família de produtos foi levado em consideração os indicadores da fábrica, sendo eleita a família de produtos o processo com melhor desempenho.

Etapa 2: desenhar os mapas atual e futuro: primeiramente definiu-se um grupo de melhorias, pois, segundo Gonzalez e Martins (2014), o trabalho em equipe é uma das principais características das organizações que buscam a fabricação Enxuta, entendendo que os colaboradores podem determinar as ações mais importantes. Toledo et al (2008) considera que o trabalho em equipe é uma boa prática de mercado, trazendo retorno representativo para os resultados almejados. Esse time de profissionais com vasta experiência nas áreas de atuação representam a visão dos especialistas das áreas de logística, manutenção, engenharia, IT (tecnologia da informação), qualidade e produção. Para fazer o mapeamento do processo é primordial o acompanhamento do processo produtivo por meio da medição dos tempos e observação das operações, seguindo o fluxo de produção, observando suas peculiaridades, as agregações com que cada operação contribui (ou não), bem como o tempo em que o produto permanece em cada uma delas (RIVERA e CHEN 2007). O diagrama do mapa atual é construído através da observação direta dos membros da equipe iniciando pelas informações do cliente. Posteriormente desenham-se os 
processos internos, destacando as informações relevantes, tais como, número de operadores, tempo ciclo, tempo de disponibilidade do equipamento, tempo de troca e estoques entre operações. O fornecedor e seu fluxo devem compor o mapeamento, seguido da inclusão dos fluxos de informação entre os processos. O mapa futuro é construído por meio da identificação de oportunidades de melhoria no processo (kaizens), que auxiliam a empresa a definir um estado futuro desejado, por meio da redução dos desperdícios encontrados.

Etapa 3: criar o plano de implementação: O processo de criação do plano de ações inicia-se pela discussão em grupo sobre as atividades necessárias para se alcançar o estado futuro planejado no mapeamento. $O$ desenvolvimento de um plano de ações visa analisar os riscos e monitorar a evolução do projeto, descrevendo todas as etapas e atividades necessárias para que os objetivos definidos sejam alcançados. A sistemática de acompanhamento das ações contemplava revisões semanais das ações com seu status reportado através das cores: (1) verde: ação realizada; (2) amarelo: data prevista; (3) vermelho: ação em atraso.

\section{UNIDADE PESQUISADA}

A empresa alvo desta pesquisa é uma fornecedora sistemista de uma grande montadora de automóveis localizada na região Sul Fluminense do estado do Rio de Janeiro e foi escolhida por acessibilidade. A participação efetiva do pesquisador, caracterizando a pesquisa-ação, norteou a investigação juntamente com uma equipe multifuncional composta por pessoas estratégicas das áreas de logística, manutenção, engenharia, IT (tecnologia da informação), qualidade e produção, com experiência prévia em mapeamento de fluxo, além de operadores dessa linha. A unidade de pesquisa selecionada para pesquisa-ação é uma multinacional Alemã a que atua no mercado de autopeça produzindo peças de suspensão traseira e dianteira. A empresa atua em 38 países, empregando aproximadamente 30.000 funcionários em 171 unidades, sendo que seis (6) delas estão no Brasil, localizadas em Camaçari-Bahia, duas (2) em Joinville-Santa Catarina, duas (2) em Campinas-São Paulo e a planta foco de estudo em Porto Real - Rio de Janeiro, atuando em três (3) grandes divisões: (i) automotiva; (ii) tubos e aços: e (iii) logística.

\section{RESULTADOS DA PESQUISA}

Como definido na metodologia a pesquisa-ação estrutura-se em: (1) definição da família de produtos; (2) desenhar os mapas atual e futuro; e (3) criar o plano de implementação.

\section{PRIMEIRA ETAPA: SELECIONANDO A FAMÍLIA DE PRODUTOS}

Uma família de produtos é composta por materiais que possuem características semelhantes e que passam pelos mesmos equipamentos, ou por uma parte deles. A linha escolhida fabricava sete modelos diferentes de produtos tecnicamente chamados de Subframe. 
A linha trabalhava por turno com um (01) operador de empilhadeira, três (03) operadores executando a montagem do produto, e um (01) operador realizando o carregamento do produto e inspeção final na linha. A demanda atendida pela linha era de 24 carros/hora e o processo de fabricação se completava após cinco (05) operações, sendo uma de pré-montagem, três de montagem e uma de picking/inspeção.

A Figura 1 ilustra o fluxograma das etapas do processo, onde: (1) A variedade de modelos fabricados segue uma sequência determinada pelo cliente e é recebida pela linha através de um sistema de troca eletrônica de dados (EDIExchange data information); (2) Os componentes eram abastecidos por um operador de empilhadeira que os posicionava na área produtiva, também conhecida como borda de linha; (3) a linha operava por lote. Montava lotes de seis modelos iguais por vez, (4) deixando-os em racks; (5) conforme a demanda do cliente os produtos acabados eram sequenciados e colocados na embalagem de entrega e enviadas ao cliente.

Figura 1 - Fluxograma

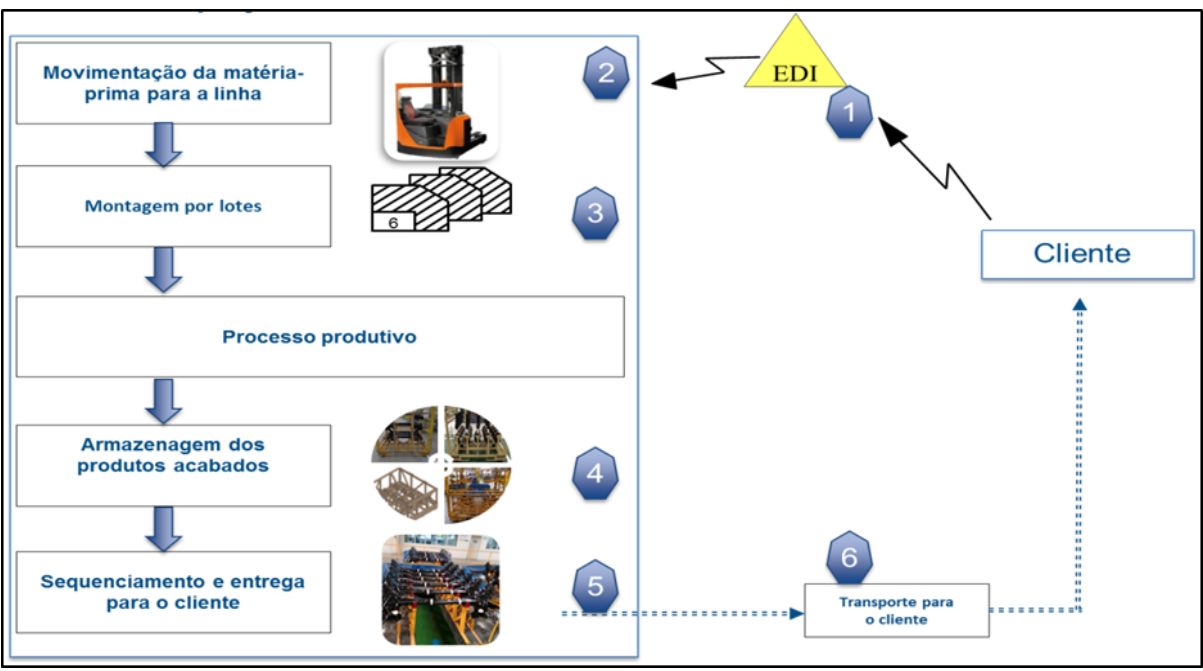

Fonte: Autoria própria (2018)

Figura 2. Legenda da Figura 1

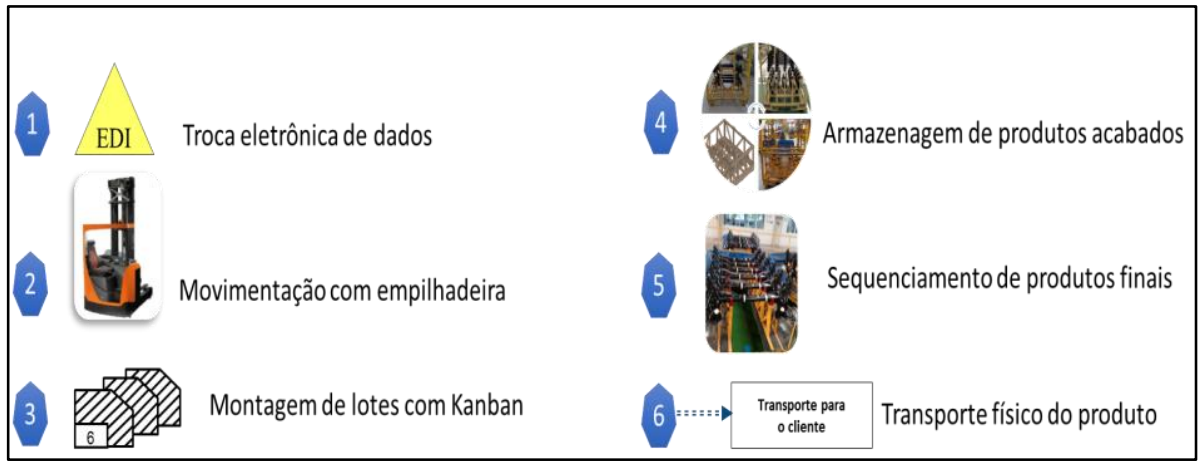

Fonte: Autoria própria (2018) 


\section{SEGUNDA ETAPA: DESENHANDO OS MAPAS: ATUAL E FUTURO}

Essa análise é citada por Folinas et al (2013) como sendo uma fase de Development of the Current State Map (desenvolvimento do mapa atual), sendo uma importante ferramenta para identificação dos desperdícios, onde através de um diagrama são identificados a performance e o fluxo de valor do processo analisado. Para realizar o diagrama é necessária uma investigação detalhada do processo. Essa investigação resulta na identificação dos desperdícios e em suas possíveis causas. Essa fase determina a real situação da linha ao iniciar o projeto de melhoria; fase essa em que o diagnóstico é registrado em forma gráfica, conforme Figura 3.

Figura 3. Mapa de fluxo de valor do estado atual

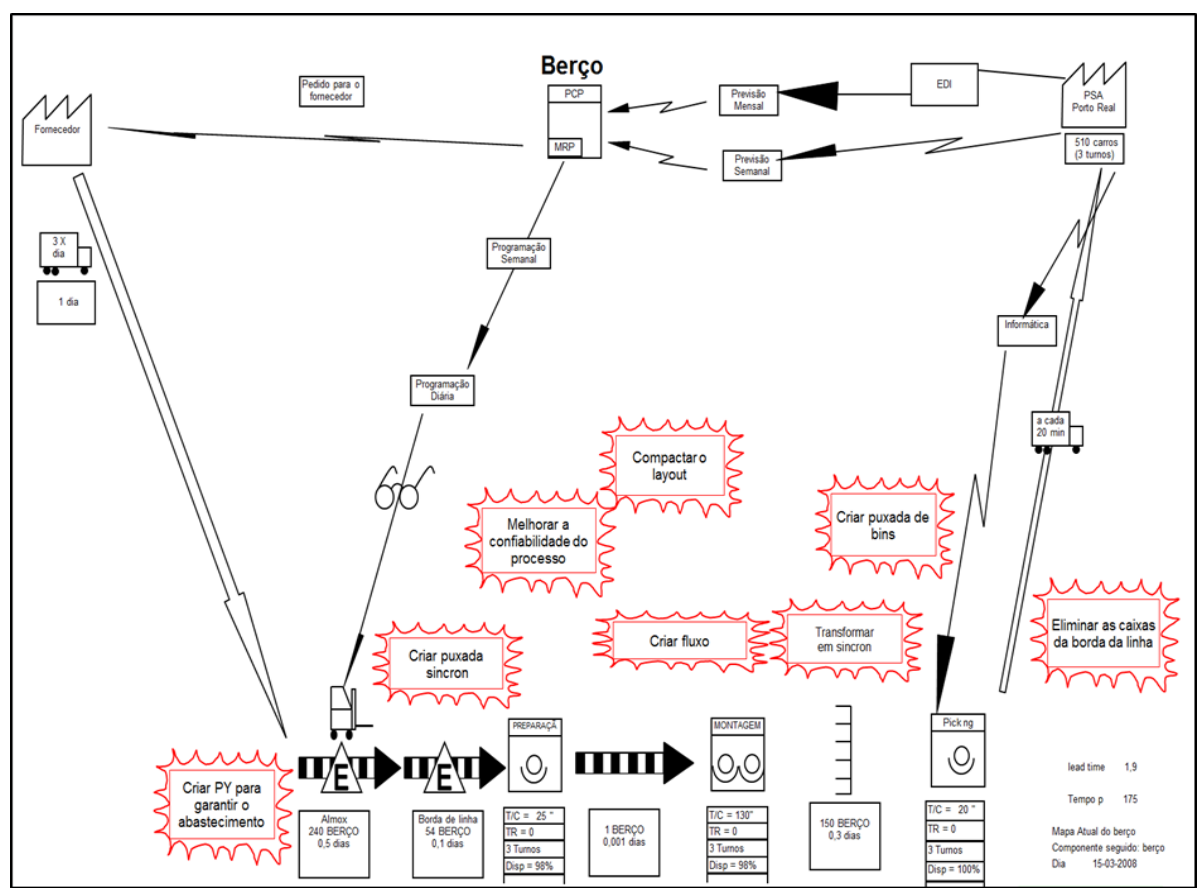

Fonte: Autoria própria (2018)

Figura 4. Ícones para o mapeamento

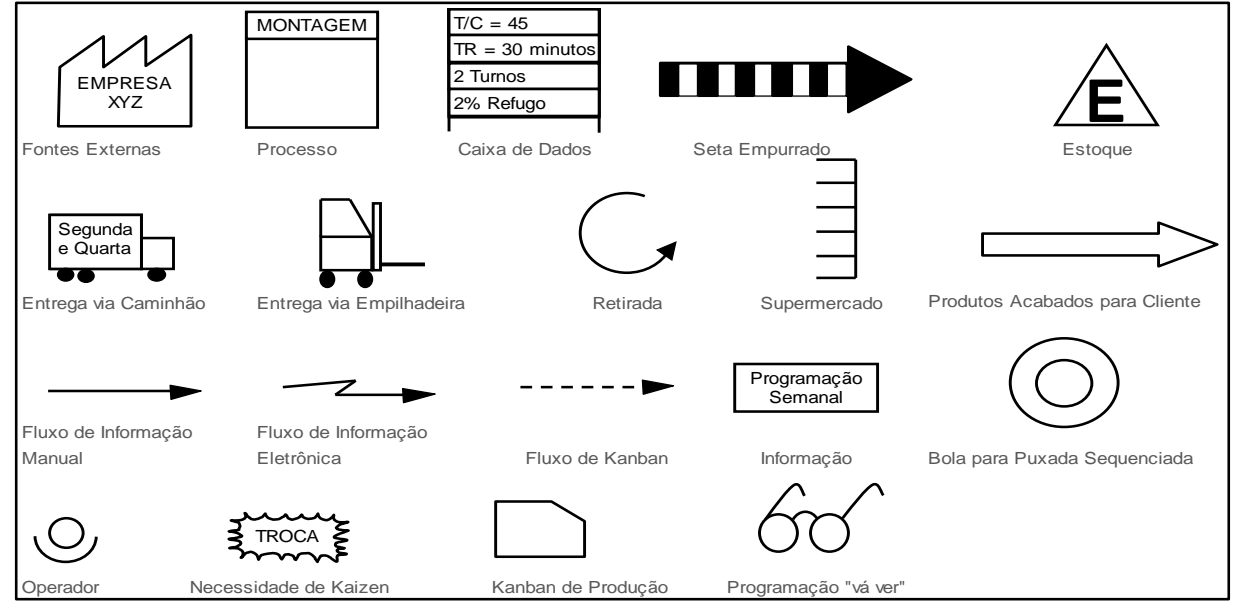

Fonte: Adaptado de Jones e Womack (2004) 
Visualiza-se na Figura 3 o fluxo completo de um componente do produto de interesse. Primeiro desenhou-se o cliente e suas informações, depois os fluxos de entrega outbound, em seguida os processos internos e, por último, o fornecedor e a entrega inbound. Nota-se por meio do mapa do estado atual que: (1) a produção era empurrada, visualizado por intermédio das setas zebradas; (2) que havia estoque entre as operações, evidenciados pelos triângulos com a letra " $E$ "; (3) que a logística abastecia a linha com uma empilhadeira seguindo uma previsão diária; (4) que havia um estoque de produtos acabados que eram puxados de acordo com a demanda sequenciada do cliente. A seguir, estão listados os pontos levantados pela equipe onde comparam-se os setes desperdícios clássicos e as evidências encontradas na linha.

Quadro 3 - Evidência dos desperdícios na linha do subframe

\begin{tabular}{|l|l|}
\hline \multicolumn{1}{|c|}{ Desperdícios } & \multicolumn{1}{c|}{ Constatações } \\
\hline Produção em excesso: & $\begin{array}{l}\text { Peças empilhadas na bancadas; } \\
\text { Estoque de produtos acabados. }\end{array}$ \\
\hline Espera: & $\begin{array}{l}\text { No momento de troca do contêiner de componentes os } \\
\text { operadores ficavam parados; } \\
\text { Operador em espera quando o rack está cheio; } \\
\text { Operador esperando para retomar a atividade enquanto a } \\
\text { máquina estava em falha; } \\
\text { Parada por problemas mecânicos. }\end{array}$ \\
\hline Transporte: & Empilhadeiras se movimentando vazias. \\
\hline Processamento & $\begin{array}{l}\text { Fazer marcação com o lacre de cor; } \\
\text { Operadores procurando ferramentas na caixa. }\end{array}$ \\
\hline Estoque: & $\begin{array}{l}\text { Muitos contêineres ao lado da linha; } \\
\text { Peças empilhadas entre as estações. }\end{array}$ \\
\hline Movimentação: & $\begin{array}{l}\text { Operadores caminhando grandes distâncias para pegar as } \\
\text { peças. }\end{array}$ \\
\hline Correção: & Operadores dedicados a inspecionar as peças acabadas. \\
\hline
\end{tabular}

Fonte: Autoria própria (2018)

Ao desenhar o mapa do estado atual, foi possível descobrir muitas atividades que não agregavam valor ou que poderiam ser realizadas de forma melhor, além de atividades que favoreciam a produção em massa, sendo essa a base para criar o mapa de valor do estado futuro (Figura 5) com base nos princípios enxutos com foco na eliminação dos desperdícios identificados.

Em consenso a equipe de melhorias definiu que: (1) seria criado um abastecimento logístico representados na Figura $5 \mathrm{com}$ sinal de supermercado; (2) criar fluxo contínuo na linha representado no mapa pelos dois círculos; (3) rebalancear a linha demonstrado através do símbolo de uma pessoa.

Por meio das análises do grupo, definiu-se uma nova configuração da estação de trabalho sugerindo-se substituir as caixas em volta da linha por racks com rodas, reduzindo-se assim a grande quantidade de inventário existente, criando supermercados de abastecimento (estoques controlados com limites mínimo e máximo) resultando na redução de área com a aproximação dos equipamentos. 
Figura 5. Mapa de fluxo de valor do estado futuro

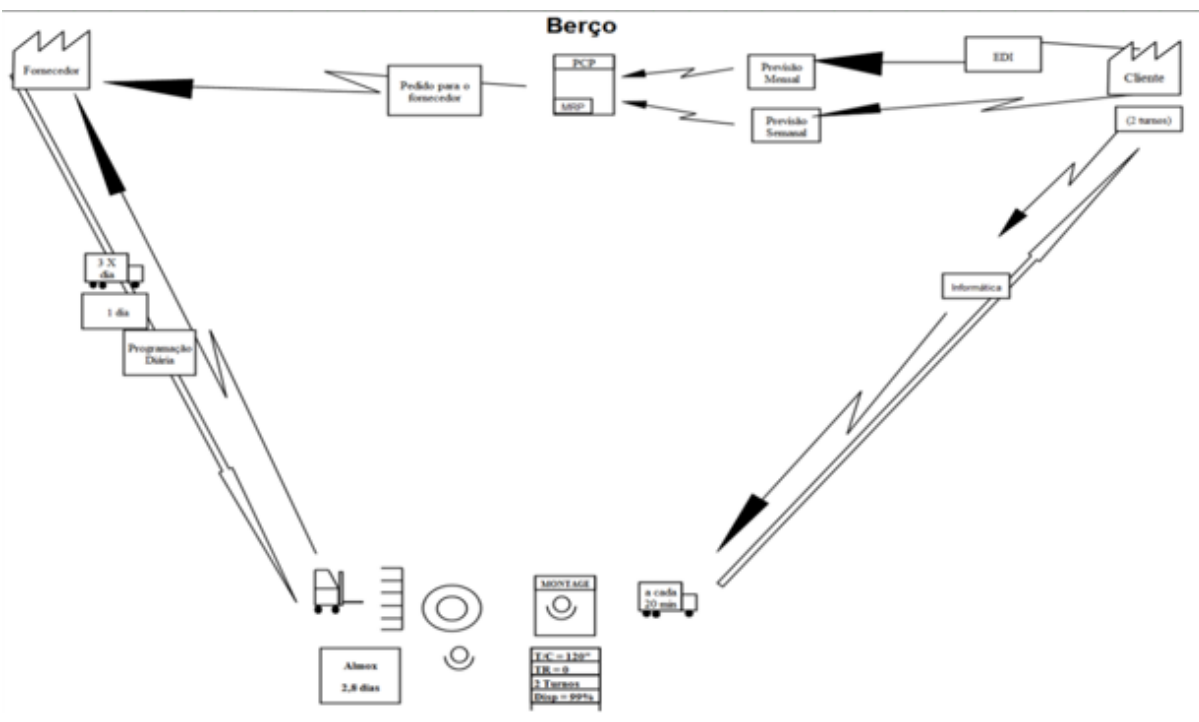

Fonte: Autoria própria (2018)

O mapeamento futuro que é entendido por Folinas et al (2013) como a fase de identificação das melhorais, define os objetivos que a equipe pretende alcançar a partir da eliminação dos problemas levantados no mapeamento do estado atual.

\section{TERCEIRA ETAPA: PLANO DE AÇÕES}

A equipe utilizou-se de um plano de ações para acompanhar e mensurar a evolução do projeto. $O$ plano de ações é o caminho para se alcançar o estado futuro planejado no mapa futuro. Esse passo envolve o esboço de um plano de implementação baseado nas expectativas do grupo, descrevendo como e aonde se pretende chegar (FOLINAS et al, 2013).

Cada uma das atividades de melhoria que tem como objetivo eliminar as atividades que não agregam valor são inclusas no plano de ações, determinando um prazo de execução da ação e é nomeado um responsável por realizar essa atividade (Quadro 4). Essas atividades são identificadas no mapeamento como Kaizens.

A sequência de implantação do plano de ações levou em consideração as restrições e necessidades de integração entre ferramentas, definindo uma sequência cronológica de aplicação para o aumento da agregação de valor, resultando na seguinte proposta:

Ferramentas da qualidade e Manutenção produtiva total: sugeriu-se a identificação dos problemas através do Andon, posteriormente anotando os problemas no quadro hora-a-hora, identificando os equipamentos críticos que devem ser foco do TPM / 5S, e monitorando os problemas através dos indicadores. Os problemas recorrentes são bloqueados através de dispositivos a prova de falhas (Pokayokes). 
Fluxo contínuo e Puxar: o fluxo contínuo deve ser o foco nessa fase aproximando os equipamentos e eliminando os estoques entre as operações, e onde não for possível aplicar essa técnica, deve-se aplicar o sistema puxado apoiado pelo kanban.

Trabalho padronizado: o trabalho padronizado deve representar os ganhos com a redução dos desperdícios, criando uma nova sequência, onde prioriza-se a agregação de valor.

Quadro 4 - Plano de ações

\begin{tabular}{|c|c|c|}
\hline Desperdícios & Kaizens & Ação / técnica Lean \\
\hline $\begin{array}{l}\text { Produção em } \\
\text { excesso: }\end{array}$ & Criar fluxo contínuo. & Fluxo contínuo \\
\hline Espera: & $\begin{array}{l}\text { Criar puxada para as embalagens pequenas } \\
\text { (BINS) para evitar que a linha pare durante a } \\
\text { troca de embalagens } \\
\text { Melhorar o balanceamento da linha para } \\
\text { reduzir a espera; } \\
\text { Melhorar a estabilidade do processo através } \\
\text { da Manutenção preventiva e preditiva. }\end{array}$ & $\begin{array}{l}\text { Puxar } \\
\text { Trabalho padronizado } \\
\text { TPM }\end{array}$ \\
\hline Transporte: & $\begin{array}{l}\text { Criar puxada sincron; } \\
\text { Criar carrinhos com lote de } 1 \text { peça para } \\
\text { retirar todos os contêineres da linha } \\
\text { reduzindo a movimentação dos operadores. }\end{array}$ & Puxar \\
\hline Processamento & $\begin{array}{l}\begin{array}{l}\text { Criar Pokayokes para garantir } \\
\text { abastecimento. }\end{array} \\
\text { abar }\end{array}$ & $\begin{array}{l}\text { Ferramentas } \\
\text { qualidade }\end{array}$ \\
\hline Estoque: & Transformar em fluxo contínuo. & Fluxo contínuo \\
\hline Movimentação & $\begin{array}{l}\text { Criar puxada sincron; } \\
\text { Compactar o layout. }\end{array}$ & $\begin{array}{l}\text { Puxar } \\
\text { Fluxo contínuo }\end{array}$ \\
\hline Correção: & $\begin{array}{l}\text { Criar Pokayokes para garantir o } \\
\text { abastecimento; } \\
\text { Melhorar a estabilidade do processo através } \\
\text { das ferramentas da qualidade evidenciando } \\
\text { uma melhora no OEE. }\end{array}$ & $\begin{array}{l}\text { Ferramentas } \\
\text { qualidade }\end{array}$ \\
\hline
\end{tabular}

Fonte: Autoria própria (2018)

\section{ANÁLISE DOS RESULTADOS}

A fase de análise, previamente embasada pela metodologia do Mapeamento do Fluxo de Valor, permitiu a identificação do cenário encontrado no início do estudo. As oportunidades de melhoria identificadas permitiram a redução dos desperdícios da linha, como descrito no Mapeamento do Fluxo de Valor futuro.

\section{FERRAMENTAS DA QUALIDADE E MANUTENÇÃO PRODUTIVA TOTAL}

O foco inicial foi a redução dos problemas de qualidade por meio da implementação da tratativa da causa-raiz dos desvios apontados pela gestão visual e pelos indicadores, amparados pela redução das paradas de linha, resultante da aplicação efetiva da manutenção produtiva total (TPM) e pelo suporte mais presente das áreas de apoio, tornando-se o alicerce que viabilizou 
as demais ações, afetando positivamente o indicador de eficiência global OEE, que passou de $78 \%$ para $96 \%$.

O Gráfico 1 demonstra a evolução do indicador com a redução dos desperdícios.

\section{Gráfico1 - Evolução do OEE}

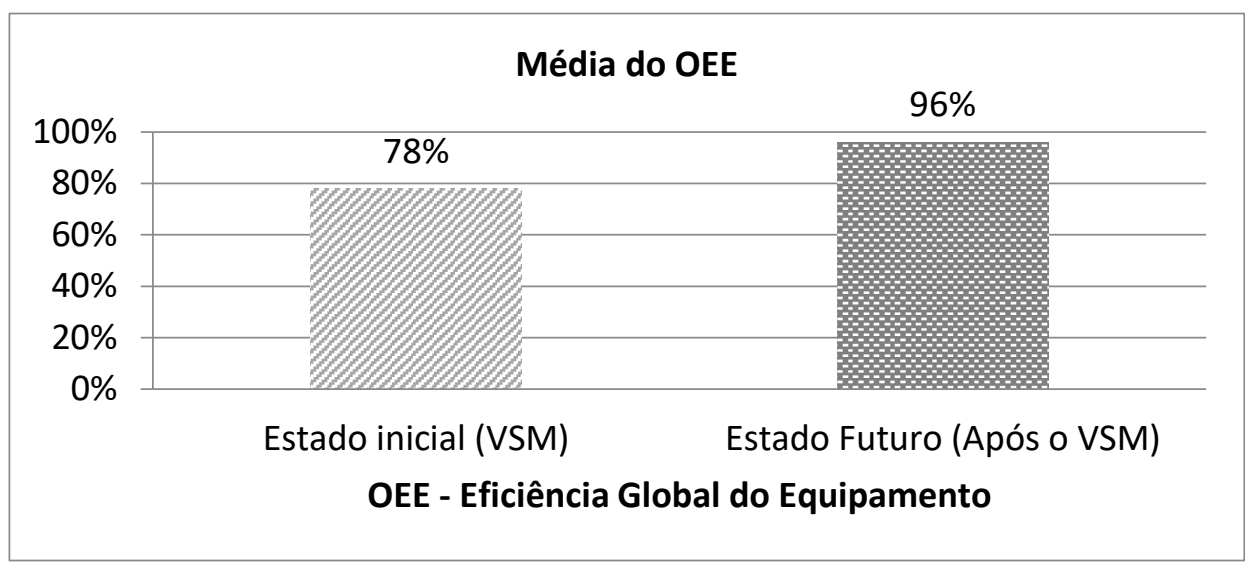

Fonte: Autoria própria (2018)

\section{FLUXO CONTÍNUO E SISTEMA PUXADO}

O fluxo de uma peça é uma técnica que exige alta confiabilidade da linha, em contrapartida há retorno em vantagem estratégica para o processo (GADELHA et al, 2015). Um ganho importante evidenciado ao final dessa etapa foi a redução de área utilizada pelo processo, reduzindo as movimentações desnecessárias, estoques intermediários e processamentos excessivos. O Gráfico 2 descreve as etapas do processo utilizados antes e após o Mapeamento de Fluxo de Valor. Observa-se nesse gráfico os resultados da aplicação do fluxo contínuo, onde no estado inicial o processo era composto de cinco (05) operações, sendo uma de pré-montagem, três de montagem e uma de picking/inspeção. Com a implementação da filosofia evidencia-se a redução, sendo ao final composta apenas de uma atividade de pré-montagem e uma de montagem.

Gráfico2 - Quantidade de operações da linha

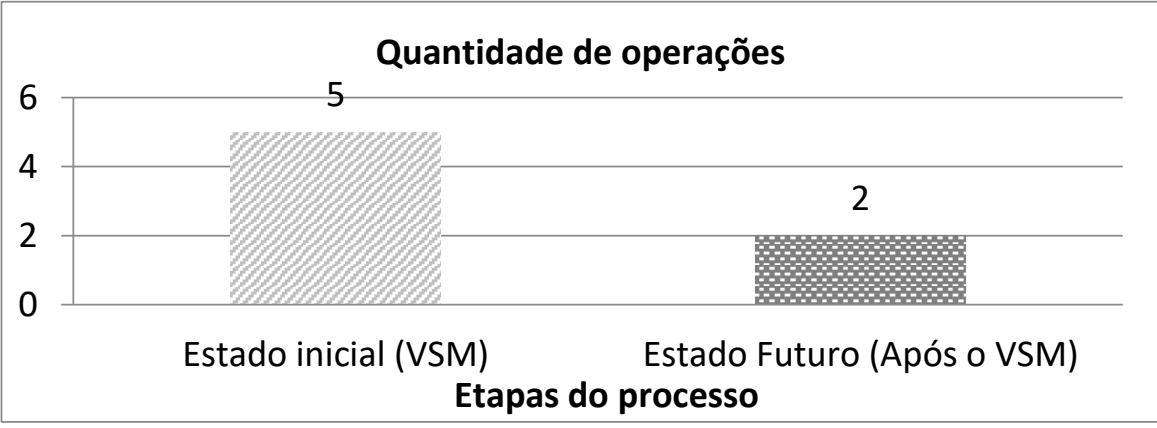

Fonte: Autoria própria (2018) 
O conceito Lean pode ser descrito como: a peça certa, na hora certa e na quantidade certa. Orientado por essa filosofia reestruturou-se o layout e alterou o conceito de abastecimento da célula. Com os componentes ao redor da linha e abastecidos pelo operador de produção em uma mesa de montagem com rodas, no qual há agregação de valor durante o deslocamento do operador reduzindo a movimentação e as paradas de linha por falta de abastecimento. $O$ comparativo entre o deslocamento do cenário durante o mapeamento inicial demonstra que para um determinado modelo, os operadores se deslocavam 72 metros (ida e volta) para pegar os três componentes principais que formavam o produto final, e os mesmos componentes, após a implantação da filosofia, são montados com o deslocamento de apenas 6 metros conforme demonstra o gráfico 3 .

Gráfico 3 - Deslocamento dos operadores

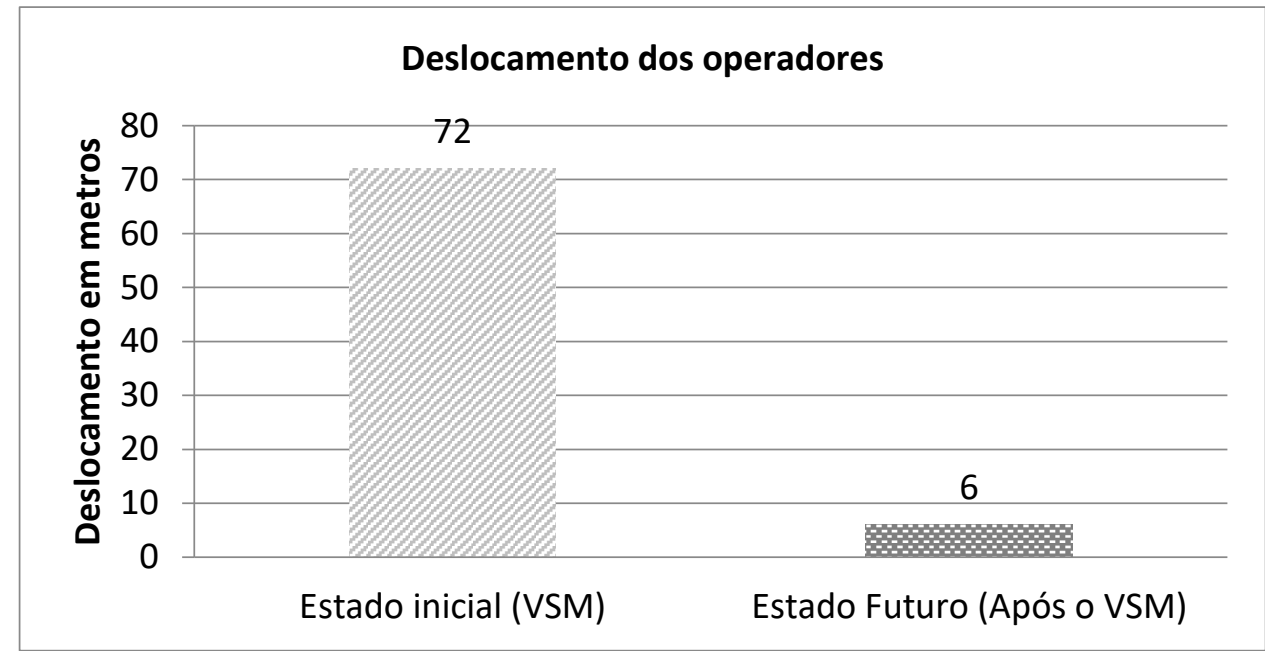

Fonte: Autoria própria (2018)

\section{TRABALHO PADRONIZADO}

Com a eliminação dos desperdícios decorrentes do Mapeamento do Fluxo de Valor, foi possível a redução da carga de trabalho dos operadores e, posteriormente, a reorganização das atividades com ganhos diretos na redução da mão de obra e a flexibilização da linha de acordo com a demanda. Observa-se na Tabela 1, que o conjunto de ações tomadas, incluindo o trabalho padrão, elevou a produtividade de 4,8 para 9,2 peças por homem/hora, consequência da redução de mão de obra e a redução de horas extras que deixaram de ser necessárias, reduzindo o efetivo da linha de cinco colaboradores com dedicação exclusiva, para dois colaboradores com $100 \%$ do tempo dedicado a linha produtiva e um operador de empilhadeira compartilhado com outras operações. 
Tabela 1 - Efetivos da linha

\begin{tabular}{|c|c|c|c|c|c|c|}
\hline \multicolumn{5}{|c|}{ Efetivo da linha } & \multicolumn{2}{|c|}{ Volume } \\
\hline 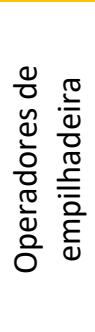 & 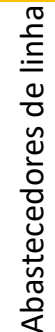 & 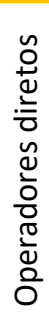 & 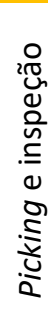 & $\begin{array}{l}\text { dे } \\
\text { ㅁ } \\
\frac{\pi}{0} \\
\frac{0}{0} \\
\frac{0}{0} \\
\frac{0}{0} \\
\frac{0}{0} \\
0\end{array}$ & 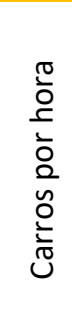 & $\begin{array}{l}\bar{\pi} \\
+0 \\
+ \\
0 \\
0 \\
\frac{\pi}{0} \\
\frac{0}{2} \\
\stackrel{+}{7} \\
\frac{7}{0} \\
0 \\
0\end{array}$ \\
\hline 1 & 0 & 3 & 1 & 5 & 24 & 4,8 \\
\hline 0,5 & 1 & 1 & 0 & 2,5 & 23 & 9,2 \\
\hline
\end{tabular}

Fonte: Autoria própria (2018)

Gráfico 4 - Produtividade

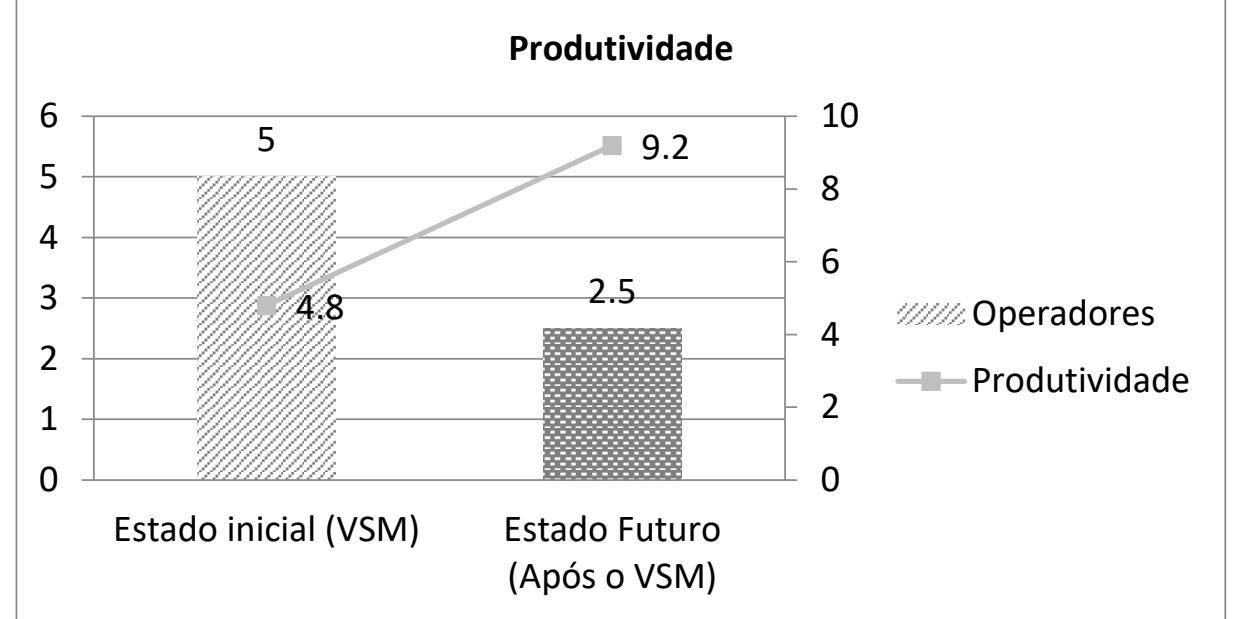

Fonte: Autoria própria (2018)

A partir do mapa atual observou-se um ganho significativo em produtividade, considerando-se o estado inicial como base. Esses resultados são ilustrados na Tabela 1 e no Gráfico 4, demonstrando que ações resultaram na evolução de $91,66 \%$ no indicador de produtividade, saindo de cinco operadores para fabricar 24 carros por hora e finalizando-se com uma redução de $50 \%$ da mão de obra, com uma capacidade produtiva de 23 carros por hora.

\section{CONCLUSÕES}

O trabalho apresenta a análise da implantação das técnicas de Manufatura Enxuta investigando um processo produtivo de uma empresa de autopeças 
estruturada por meio do método de Mapeamento de Fluxo de Valor sistematicamente suportado por uma pesquisa-ação.

O objetivo principal da pesquisa foi atingido, pois a aplicação do Mapeamento do Fluxo de Valor permitiu identificar os desperdícios inerentes ao processo, gerando os seguintes resultados: (1) redução dos problemas de qualidade por meio da tratativa da causa-raiz dos desvios; (2) aplicação efetiva da Manutenção Produtiva Total; e (3) suporte mais presente das áreas de apoio, foram fundamentais para o aumento da performance do indicador de OEE em 18\%. A aplicação das técnicas: (A) fluxo contínuo: resultando na redução da movimentação de 72 para 6 metros, além da simplificação do processo e consequente redução de 3 elementos de trabalho; (B) sistema puxado: que promoveu uma redução da movimentação dos operadores e a eliminação das paradas por downtimes; e (C) trabalho padronizado: que reorganizou o processo, promovendo uma melhoria na produtividade de 91,66\%. Esses resultados corroboram com os ganhos obtidos por diversos autores através da implementação parcial ou total das técnicas, como exemplo: Gadelha et al. (2015) que obteve um ganho de produtividade de 56\%; Júnior, Siluk e Nara (2015) obtiveram aumento de 37\% na produção por dia; Guimarães et al. (2014) com um aumento desse indicador de 35,9\%; Mesquita, Mesquita e Souza (2014), apresentando $17 \%$ de melhoria; Salgado et al onde a eficiência aumentou em 67,2\%; Das, Venkatadri e Pande (2014) obtiveram um ganho de $77 \%$ na produtividade; e com o potencial de ganho de até $19 \%$ caso a empresa implemente todas as práticas propostas (LIMA et al, 2016);

Como sugestão para estudos futuros, recomenda-se avaliar por meio do Mapeamento de Fluxo o nível de valor agregado que as empresas realmente praticam em seus processos comparando indústrias de diferentes seguimentos. 


\title{
Empirical results of Value Stream Mapping implementation in an automotive company
}

\begin{abstract}
For eliminate activities that consume resources but are not add value companies have been used Lean Manufacturing concepts resulting in significant gains for the company. Understanding this problem, the article uses the research-action methodology applied in the production process of an assembly line of an automotive company in the South Fluminense region in Brazil. The VSM identified wastes in the process, motivating the application of quality tools, total productive maintenance, continuous flow, pull system and standardized work, resulting in the increase of productivity by $91.66 \%$, increase of OEE of $18 \%$, reduction of movement from 72 to 6 meters, and simplify the production process eliminating 3 stages.
\end{abstract}

KEYWORDS: Lean Manufacturing. Lean production. Value Stream Mapping. 
AR, R.; AL-ASHRAF, M. Production Flow Analysis through Value Stream Mapping: A Lean Manufacturing Process Case Study. Procedia Engineering, v. 41, p. 17271734, 2012. crossref

AZZAM, S. R.; ARIAS, L. C.; ZHOU, S. Managing a Manufacturing System with Integration of Walking Worker and Lean Thinking. World Academy of Science, Engineering and Technology, v. 55, p. 618-620, 2011.

BARBALHO, S. C. M; NITZSCHE, M. C. M; DANTAS, A. S. Melhoria de processos na gestão pública: uma pesquisa-ação com foco nas atividades administrativas de um programa de intercâmbio estudantil de uma universidade pública. Process improvement on public administration: an action research focusing on adminstrative activities of student mobility program of a Brazilian public university. Produção Online, v. 17, n. 2, p. 406-439, 2017. crossref

BARTZ, A. P. B.; WEISE, A. D.; RUPPENTHAL, J. E. Aplicação da manufatura enxuta em uma indústria de equipamentos agrícolas. Ingeniare. Revista chilena de ingeniería, Santa Maria, v. 2, n. 1, p. 147-158, 2013.

BERKENBROCK, T.; RENÓ, G.W.S.; MARTINS, A.A.; SEVEGNANI, G.; FISCHER. D. A. Estudo do trabalho padrão em linhas de montagem de refrigeradores. In: Encontro Nacional de Engenharia de Produção, 2009, Salvador, BA, Brasil, Anais... Salvador BA: XXIX ENEGEP, 2009.

BHAMU, J.; SANGWAN, K. S. Lean Manufacturing: literature review and research issues. International Journal of Operations e Production Management, v.34, n.7, p.876-940, 2014. crossref

BIEHL, C.N.; SELLITTO, A. M. TPM e manutenção autônoma: estudo de caso em uma empresa da indústria metal-mecânica. Revista Produção Online, v. 15, n. 4, p. 1123-1147, 2015. crossref

BUENO. W. P.; VEIGA, C. H. A. Estudo do mapeamento de fluxo de valor na formação de cabedal de calçados femininos. Revista Gestão Industrial, Ponta Grossa, v. 12, n. 4, p. 127-149, 2016. Disponível em:

<https://periodicos.utfpr.edu.br/rgi>. Acesso em: 24 de Abril de 2018.

BULHÕES, I. R.; PICCHI, F. A. Diretrizes para a implementação de fluxo contínuo em obras de edificações. Ambiente Construído, v. 11, n. 4, p. 205-223, 2011. crossref 
CALSAVARA, N. A. Aplicação do pensamento Lean Office e mapeamento do fluxo de valor no processo de concepção de unidades bancárias de uma empresa do setor financeiro. GEPROS. Gestão da Produção, Operações e Sistemas, v. 11, n. 3, p. 105-117, 2016.

CELIS, O.L. M.; GARCÍA, J. M. S. Modelo tecnológico para el desarrollo de proyectos logísticos usando Lean Six Sigma. Estudios gerenciales, v. 28, n. 12, p. 23-4, 2012.

DAL, V.; AKÇAGÜN, E.; YILMAZ, A. Using Lean Manufacturing Techniques to Improve Production Efficiency in the Ready Wear Industry and a Case Study. FIBRES e TEXTILES in Eastern Europe, v. 21, n. 4, p. 16-22, 2013.

DAS, B.; VENKATADRI, U.; PANDEY, P. Applying Lean Manufacturing system to improving productivity of airconditioning coil Manufacturing. The International Journal of Advanced Manufacturing Technology, v. 71, n. 4, p. 307-323, 2014. crossref

DEIFA, A. M.; ELMARAGHY, H. Cost performance dynamics in Lean production leveling. Journal of Manufacturing Systems, v. 33, p. 613-623, 2014. crossref

DOMINGO, R.; AGUADO, S. Overall Environmental Equipment Effectiveness as a Metric of a Lean and Green Manufacturing System. Sustainability, v. 7, p. 90319047. 2015. crossref

DUARTE, S; CRUZ M. V. Green and Lean implementation: an assessment in the automotive industry. International Journal of Lean Six Sigma, v.8, n. 1, p. 65-88. 2017. crossref

FILHO, M. G.; PIRES, S. R. I. Os principais passos adotados na aplicação de kaizen em fabricante de componentes industriais seriados. The main steps adopted in the application of kaizen in an industrial serial components manufacturer. Revista Produção Online, v. 17, n. 4, p. 1160-1178, 2017. crossref

FOLINAS, D.; AIDONIS, D.; TRIANTAFILLOU, D; MALINDRETOS, G. Exploring the greening of the food supply chain with Lean thinking techniques. Procedia Technology, v. 8, p. 416-424, 2013. crossref

FREITAS, W.R.S.; JABBOUR, C.J.C.; TEIXEIRA, A.A.; JABBOUR, A.B.L.S. Gestão de recursos humanos e manufatura enxuta: evidências empíricas do setor automotivo brasileiro. Production, v. 24, n. 2, p. 451-461, 2014. crossref 
GADELHA, F. C.; BESSA, J. A.; MOURA, L B.; BARROSO, D. A.; MENEZES, J.W.M.; ALEXANDRIA, A. R. Alteração de um layout funcional para layout celular motivado pelos fundamentos da manufatura enxuta: estudo de caso em indústria de transformadores. Holos, v. 31, n. 6, p. 156-169, 2015. crossref

GAUTAM, R.; KUMAR, S.; SINGH, S. Kaizen Implementation in an Industry in India: A Case Study. International Journal of Research in Mechanical Engineering e Technology, v. 2, n. 1, p. 25-3, 2012.

GOBBO, S. C. O.; RODRIGUES, J.S.; JUNIOR, J. A.G.; FUSCO, J.P.A. Uma análise das estratégias de manufatura adotadas por seis montadoras da indústria automobilística mundial. GEPROS. Gestão da Produção, Operações e Sistemas, v. 5, n. 3, p. 11-28, 2010.

GONZALEZ, R. V. D.; MARTINS, M. F. Knowledge Management: an Analysis From the Organizational Development. Journal of Technology Management e Innovation, v. 9, n. 1, p. 131-147, 2014. crossref

GUIMARÃES, J.C.F; REIS, Z.C.; SEVERO, E.A; DORION, E.C.H ; OLEA, P. M. Implantação do sistema Lean production: inovação organizacional em uma indústria moveleira. Sistema e Gestão, v. 9, n. 4, p. 452-464. 2014. crossref

JABBOUR, A.B.L,S.; TEIXEIRA, A. A.; FREITAS, W. R. S; JABBOUR, C.J.C. Análise da relação entre manufatura enxuta e desempenho operacional de empresas do setor automotivo no Brasil. Revista de Adminstração, v. 48, n. 4, p. 843-856.

JASTI, N. V. K.; KODALI, R. A literature review of empirical research methodology in Lean Manufacturing. International Journal of Operations e Production Management, v. 34, n. 8, p. 1080-1122, 2014. crossref

JEONG, B. K.; YOOM, T. E. Improving IT process management through value stream mapping approach: a case study. JISTEM - Journal of Information Systems and Technology Management. v. 13, n. 3, p. 389-404. 2016.

JONES, D.; WOMACK, J. Mapeamento do fluxo de valor estendido. São Paulo: Lean Institute Brasil. 2004).

JÚNIOR, A. L. N.; SILUK, J. C. M.; NARA, E. O. B. Estudo de um fluxo interno de materiais baseado na filosofia Lean Manufacturing. Production, v. 25, n. 3, p. 691-700. 2015. crossref

LIMA, D. F.S.; ALCANTARA, P. G. F.; SANTOS, L. C.; SILVA, L. M. F.; SILVA, R. M. Mapeamento do fluxo de valor e simulação para implementação de práticas Lean 
em uma empresa calçadista. Revista Produção Online, v. 16, n. 1, p. 366-392, 2016. crossref

LIMA, M. L. S. C.; ZAWISLAK, P. A. A produção enxuta como fator diferencial na capacidade de fornecimento de PMEs. Revista Produção, v. 13, n. 2, p. 57-69. 2003. crossref

LOSONCI, D.; DEMETER, K.; JENEI, I. Factors influencing employee perceptions in Lean transformations. International Journal of Production Economics, v. 131, n. 1, p. 30-43. 2011. crossref

MACEDO, M.; FISCHER, D. A.; GAUTHIER, F. O.; TRINDADE, E. P. Aplicação da manufatura enxuta para melhoria dos resultados operacionais no processo de macharia de uma fundição: Estudo de caso Docol. Espacios, v. 35, n. 3, p. 1-12, 2014.

MARCHWINSKI, C.; SHOOK, J. Léxico Lean: glossário para praticantes do pensamento Lean. (2 ed). São Paulo: Lean Institute Brasil. 2007.

MARODIN, G. A.; FRANK A. G.; TORTORELLA G. L.; SAURIN, T. A. Contextual factors and Lean production implementation in the Brazilian automotive supply chain. Supply Chain Management: An International Journal, v. 21, n. 4, p. 417432, 2016. crossref

MARODIN, G.; ECKERT, C. P.; SAURIN, T. A. Avançando na implantação da logística interna Lean: dificuldades e resultados alcançados no caso de uma empresa montadora de veículos. Revista Produção Online, v. 12, n. 2, p. 455-479, 2012. crossref

MARODIN, G.; SAURIN, T. A. A influência das práticas de produção enxuta nos atributos qualificadores das células de manufatura. Revista Produção Online, v. 13, n. 4 , p. 1252-1275, 2013. crossref

MENDES, A. A; RIBEIRO, J. L. D. Estabelecimento de um plano de Manutenção baseado em análises quantitativas no contexto da MCC em um cenário de produção JIT. Production, v. 24, n. 3, p. 675-686, 2014. crossref

MESQUITA, D. C. V; MESQUITA, W. G.; SOUZA, L. R. S. Implementação do mapeamento de fluxo de valor de uma montadora de veículos, denominada empresa Beta. Exacta, v. 12, n. 2, p. 197-208, 2014. crossref 
MILNITZ, D.; TUBINO D. F. Aplicação do método de Mapeamento de Fluxo de Valor no setor de engenharia de uma empresa têxtil. Exacta - EP, v. 11, n. 2, p. 199-212. 2013.

MOURA, D. A.; BOTTER, R. C. Caracterização do sistema de coleta programada de peças, Milk Run. RAE-eletrônica, v. 1, n. 1, p. 1-14, 2002. crossref

PEINADO, J.; GRAEML, A. R. A. prática da gestão de operações nas organizações. RAE-Revista de Administração de Empresas, v. 54 n. 5, p. 483-495. 2014. crossref

PINTO, J. S.; SCHUWARTEN, L. A.; JÚNIOR, G. C. O.; NOVASKI, O. Proposal the application of DMAIC tools and value stream mapping under the perspective of the Lean philosophy for process improvement: A case study. Brazilian Journal of Operations e Production Management, v.14, n. 4, p. 556-566, 2017. crossref

PRATES, C. C.; BANDEIRA, D. L. Aumento de eficiência por meio do mapeamento do fluxo de produção e aplicação do Índice de Rendimento Operacional Global no processo produtivo de uma empresa de componentes eletrônicos. Gestão e Produção, v. 18, n. 4, p. 705-718. 2011. crossref

RAJENTHIRAKUMAR, D.; SHANKAR G.R. Analyzing the benefits of Lean tools: A consumer durables Manufacturing company case study. International Journal of Engineering, v. 3, p. 335-339. 2011.

RAJENTHIRAKUMAR, D; SRIDHAR, R. Development of Lean assembly line - A case study. International Journal of Lean Thinking, v. 5, n. 1, p. 1-8. 2014.

RAMESH, V.; KODALI, R. A decision framework for maximising Lean Manufacturing performance. International Journal of Production Research, $v$. 50, n. 8, p. 2234-2251. 2011. crossref

RAPOSO, C. F. C. Overall equipment effectiveness: aplicação em uma empresa do setor de bebidas do pólo industrial de Manaus. Revista Produção Online. v. 11, n. 3 , p. 648-667, 2011. crossref

RAVE, J. P.; ROTTA, D. L.; SÁNCHEZ, K.; MADERA, Y.; RESTREPO, G. RODRÍGUEZ, M.; VANEGAS, J.; PARRA, C. Identificación y caracterización de mudas de transporte, procesos, movimientos y tiempos de espera en nueve pymes manufactureras incorporando la perspectiva del nivel operativo. Ingeniare: Revista Chilena de Ingeniería, Arica, v. 19, n. 3, p. 396-408, 2011. crossref 
REBELATO, M. G; MADALENO, L. L; RODRIGUES, A. M. Um estudo sobre a aplicabilidade do Just-in-time na fabricação do Etanol. Revista Produção Online, v. 12 , n. 3, p. $703-728,2012$. crossref

RIEZEBOS, J. Shop Floor Planning and Control in Team-based Work Processes. International Journal of Industrial Engineering and Management (IJIEM), v. 4, n. 2, p. 51-56, 2013.

RIVERA, L.; CHEN, F. F. Measuring the impact of Lean tools on the cost-time investment of a product using cost-time profiles. Robotics and ComputerIntegrated Manufacturing, v. 23, n. 6, p. 684-689. 2007. crossref

RODRÍGUEZ, A. M. P. Aplicación de la herramienta Value Stream Mapping a uma empresa embaladora de productos de vidrio. Entramado. V. 13, n. 1, p. 262-277, 2017. crossref

ROLDAN, F.; MIYAKE, D. I. Mudanças de forecast na indústria automobilística: iniciativas para a estruturação dos processos de tomada de decisão e processamento da informação. Gestão e Produção, v. 11, n. 3, p. 413-427. 2004. crossref

ROTHER, M.; SHOOK, J. Aprendendo a enxergar: mapeando o fluxo de valor para acrescentar valor e eliminar o desperdício. São Paulo: Lean Institute do Brasil. 2012.

ROYER, R.; FERREIRA, A.; SAVADRA, L. P. Mapa de fluxo de valor aplicado em uma micro cervejaria. Revista Gestão Industrial, Ponta Grossa, v. 14, n. 1, p. 01-18, jan./mar. 2018.

SALGADO, E. G.; MELLO, C. H. P.; SULVA, C. E. S.; OLIVEIRA, E. S.; ALMEIDA, D. A. Análise da aplicação do mapeamento do fluxo de valor na identificação de desperdícios do processo de desenvolvimento de produtos. Gestão e Produção, v. 16, n. 3, p. 344-356. 2009. crossref

SAURIN, T. A.; RIBEIRO, J. L. D.; MARODIN, G. A. Identificação das oportunidades de pesquisa a partir de um levantamento da implantação da produção enxuta em empresas do Brasil e do exterior. Gestão da Produção, 17(4), 829-841. 2010. crossref

SILVA, B. M. S. R; MEDINA, F; ROCHA, H. V.A; OLIVEIRA, A. R. Uso do indicador de eficácia global de equipamentos como ferramenta para melhoria contínua: estudo de caso aplicado à produção farmacêutica. Sistemas e Gestão, v. 11, n. 1, p. 49-60, 2016. crossref 
SILVA, I. B.; MIYAKE, D. I.; BATOCCHIO, A.; AGOSTINHO, O. L. Integrando a promoção das metodologias Lean Manufacturing e Six Sigma na busca de produtividade e qualidade numa empresa fabricante de autopeças. Gestão e Produção, v. 18, n. 4, p. 687-704, 2011. crossref

TEICHGRÄBER, U. K.; BUCOURT, M. Applying value stream mapping techniques to eliminate non-value-added waste for the procurement of endovascular stents. European Journal of Radiology, v. 81, p. 47-52, 2012. crossref

TOLEDO, J. C.; SILVA, S. L.; ALLIPRANDINI, D. H.; MARTINS, M. F; FERRARI, F. M. Práticas de gestão no desenvolvimento de produtos em empresas de autopeças. Produção, v. 18, n. 2, p. 405-422, 2008. crossref

UHRIN, Á.; CÁMARA, S. B.; FUENTES, J. M. Lean production, workforce development and operational performance. Management Decision, v. 55, n. 1, p. 103-118. crossref

VINODH, S.; SOMANAATHAN, M.; ARVIND, K.R. Development of value stream map for achieving Leanness in a Manufacturing organization. Journal of Engineering, Design and Technology, v. 11, n. 2, p. 129-141, 2013. crossref

VOTTO, R. G; FERNANDES, F. C. F. Produção enxuta e teoria das restrições: proposta de um método para implantação conjunta na Indústria de Bens de Capital sob Encomenda. Gestão e Produção, v. 21, n. 1, p. 45-63, 2014. crossref

ZATTAR, I. C.; SILVA, R. R. L; BOSCHETTO, J. W. Aplicações das ferramentas Lean na área da saúde: revisão bibliográfica. Journal of Lean Systems, v. 2, n. 2, p. 688, 2017.

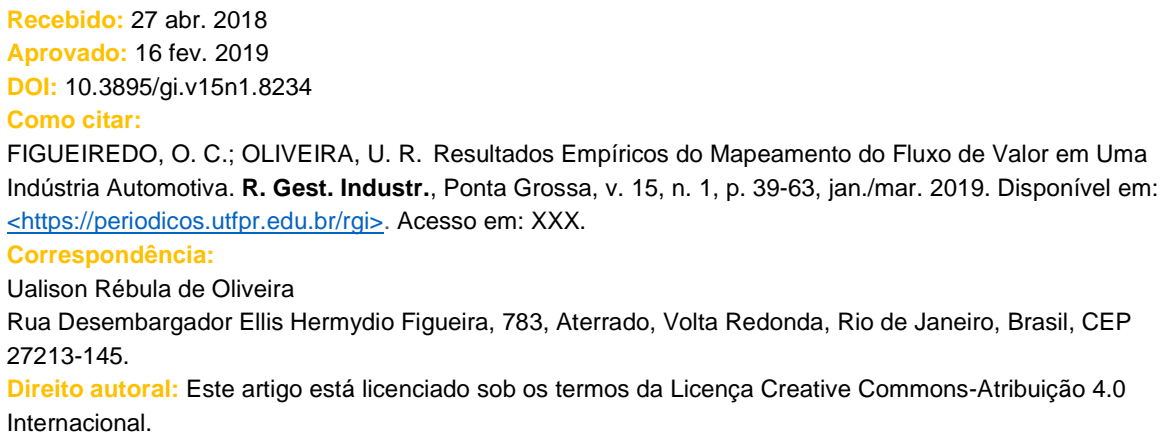

